\title{
Determinants of expiratory airflow in patients with chronic airways obstruction
}

\author{
ALASTAIR H. CAMPBELL and L. W. FAULKS \\ Repatriation General Hospital, Heidelberg, Victoria, Australia
}

\begin{abstract}
This paper examines the relationship between the intrathoracic and bronchial pressures and the flow time course during forceful expiration in patients with severe chronic airways obstruction and tracheobronchial collapse.

After an initial peak flow, the flow rate $(\dot{V})$ of forceful expirations usually fitted the patient's maximum expiratory flow volume (MEFV) curve. The great reduction in flow after the peak corresponded to a large reduction of the thoracic gas volume (TGV) due to the high intrathoracic pressures compressing the lungs. An occasional slight rise in flow in the middle of the slow phase corresponded to an increase of the TGV due to reduction of the intrathoracic pressure. The early peak flow was found to exceed considerably the $\dot{V}$ expected from the MEFV curve. Pressure measurements in the right lower lobe bronchus suggest that this could be due to at least two factors: first, a rapid reduction in bronchial volume and, secondly, a short time lag before flow limitation develops, allowing initial rapid transit of air.

During a forced expiration, flow limitation was initiated when the equal pressure points were sufficiently upstream to allow compression of small as well as large airways. The evidence suggested that tracheobronchial collapse followed the initiation of flow limitation and was unlikely to have had more than a slight subsidiary effect on the maximum flow. Due to greater compression, the TGV and hence the flow rate were smaller during a forceful expiration than during a less forceful expiration.
\end{abstract}

Hyatt, Schilder, and Fry (1958) originally described the unique relationship between maximum expiratory flow rate $(\mathbf{V}$ max) and lung volume. At a lung volume of less than 60 to $70 \%$ of the vital capacity (VC) the expiratory flow cannot be increased above a certain rate by increasing the expiratory effort, that is, flow limitation develops. The $\dot{V}$ max is then related to the lung volume. The limitation of flow is believed to be due to critical compression of the airways by the intrathoracic pressure, so that increases in the driving pressure are balanced by increases of resistance.

Because of the relationship between lung volume and $V$ max, normal subjects produce forced expiratory spirograms and flow volume curves which show that the flow rate during expiration diminishes with time or decreasing volume although the expiratory effort may be maintained.

From the point of view of understanding lung mechanics there are advantages in considering the thoracic gas volume at alveolar pressure. When high intrathoracic pressures are applied the compression of intrathoracic gas is sufficient to reduce its volume appreciably. It is this volume rather than that calculated from the total lungo capacity and the expired volume which affectso the diameter and geometry of the airways (Ingram and Schilder, 1966).

With severe airway obstruction the forced ex piratory spirograms and flow-volume curves differ from normal by showing an initial peak flowo followed by rapid reduction of flow which then becomes slow and declines slightly with time and? expired volume changes. This type of flow pattern is apparently related to the severity of airway obstruction (Jordanoglou and Pride, 1968).

In the present study, factors leading to thisw flow pattern were studied. Particular attention was paid to the time relationships of flow too thoracic gas volume, intrathoracic pressure, ando pressures measured in the right lower lobe bronchus.

\section{METHODS AND MATERIALS}

The patients were four men known to have chronico bronchitis with severe reduction of forced respiratory volume, only slightly improved by a bronchodilator. 
All four patients had gross collapse of the mainstem bronchi and trachea during forced expiration observed bronchoscopically. Various physical characteristics are summarized in Table I.

\section{T A B L E I}

\begin{tabular}{|c|c|c|c|c|c|c|c|c|c|c|}
\hline Patient & $\begin{array}{l}\text { Age } \\
\text { (yr) }\end{array}$ & $\underset{(\mathrm{cm})}{\mathrm{Ht}}$ & $\left|\begin{array}{c}\mathbf{W t} \\
(\mathbf{k g})\end{array}\right|$ & $\underset{\text { (l.) }}{\text { FEV }_{1}}$ & $\begin{array}{l}\text { VC } \\
\text { (1.) }\end{array}$ & $\begin{array}{l}\text { RV } \\
\text { (l.) }\end{array}$ & $\mid \begin{array}{c}\text { TLC } \\
\text { (I.) }\end{array}$ & $\underset{\text { (1.) }}{\text { FRC }}$ & $\mid \begin{array}{l}\text { Alv. } \\
\mathrm{N}_{2} \% \\
\text { after } \\
7 \mathrm{~min}\end{array}$ & $\begin{array}{c}\text { Pel } \\
\max \\
(\mathrm{cm} \\
\left.\mathbf{H}_{\mathbf{2}} \mathrm{O}\right)\end{array}$ \\
\hline $\begin{array}{l}1 \\
2 \\
3 \\
4\end{array}$ & $\begin{array}{l}63 \\
65 \\
59 \\
52\end{array}$ & $\begin{array}{l}175 \\
170 \\
166 \\
173\end{array}$ & $\begin{array}{l}68 \\
69 \\
54 \\
58\end{array}$ & $\begin{array}{l}0 \cdot 89 \\
0 \cdot 34 \\
0 \cdot 54 \\
0 \cdot 39\end{array}$ & $\begin{array}{l}2.94 \\
1.86 \\
1.99 \\
1.95\end{array}$ & $\begin{array}{l}4 \cdot 18 \\
5 \cdot 30 \\
3 \cdot 72 \\
4 \cdot 46\end{array}$ & $\begin{array}{l}7 \cdot 12 \\
7 \cdot 16 \\
5 \cdot 71 \\
6 \cdot 41\end{array}$ & $\begin{array}{l}5 \cdot 35 \\
6 \cdot 35 \\
4 \cdot 72 \\
5 \cdot 25\end{array}$ & $\begin{array}{r}3 \cdot 2 \\
7 \cdot 2 \\
10 \cdot 0 \\
5 \cdot 0\end{array}$ & $\begin{array}{l}10.0 \\
10.0 \\
10.5 \\
15.0\end{array}$ \\
\hline
\end{tabular}

Pel max is the static recoil pressure at full inspiration.

Records were obtained of intrathoracic (ossophageal) pressure, flow rate, and flow volume both during tidal breathing and during expirations from the position of full inspiration. Several measurements were made after maximum and various degrees of submaximum effort. In three subjects, bronchial or tracheal pressures were recorded simultaneously. During these tests the patients, with noseclips applied, exhaled through a mouthpiece of internal diameter $2.3 \mathrm{~cm}$ into the Fleisch head of a pneumotachograph.

The records of oesophageal pressure, bronchial pressure, inspired and expired volume, and total air flow were made on a multi-channel recorder (Offner Dynograph R).

Oesophageal pressure was determined using a balloon catheter system connected to a Statham strain gauge (PM 6). For measurements of compliance and maximum 'negative' intrathoracic pressure $0.2 \mathrm{ml}$ of air was inserted. Under these conditions the characteristics of the recording system were similar to those used by Milic-Emili, Mead, Turner, and Glauser (1964). When the oesophageal pressure was likely to exceed values found in quiet breathing, $3.0 \mathrm{ml}$ of air were inserted into the balloon. Frequent checks on zero and balloon volume were performed during the tests. Flow of air was determined by measuring the pressure gradient across a Fleisch head capable of measuring flow rates of at least $800 \mathrm{1} / \mathrm{min}$ connected to a pneumotachograph. This signal was integrated to give a simultaneous volume output.

In three of the patients bronchial pressures were recorded with a radio-opaque catheter (internal diameter $2 \mathrm{~mm}$, external diameter $3.2 \mathrm{~mm}$ ). The procedure adopted has been described previously (Campbell and Faulks, 1969).

With the bronchial catheter in situ during expiration, bronchial pressures could be raised somewhat by the presence of the catheter in the bronchus. However, this effect would be slight in the larger airways and any exaggeration of the pressures would have been unlikely to bias the conclusion reached.

Simultaneous measurements of the oesophageal pressure and flow through the Fleisch head during sharp transient increases of intrathoracic pressure showed little difference in the time response for each system. The oesophageal pressure signal preceded the flow signal by 0.005 second or less. Correction for this small difference made no significant differences to the results. It was considered that it could be safely ignored. The time responses of pressure recording through the bronchial catheter system and oesophageal balloon system were also almost identical.

In examining the relationship between $\dot{V} \max$ and lung volume, the degree of thoracic inflation cannot be accurately determined by measuring only the volume displaced at the mouth (Ingram and Schilder, 1966). Due to compression, the lung volume is less than the volume calculated by subtracting the air exhaled from the total lung capacity. The difference between the actual lung volume and that calculated from the air exhaled increases with the intrathoracic pressure and the lung volume. Although a volume displacement body plethysmograph is the best method of measuring the thoracic gas volume during expiration, this was not considered practicable during bronchial pressure recordings. Consequently, to obtain the total gas volume (TGV) at any point in expiration, the lung volume calculated from the air exhaled was corrected by a factor derived from the ratio of atmospheric pressure to the intrathoracic pressure at that point. In this calculation, the alveolar pressure is more relevant than the intrathoracic pressure, but the clastic recoil was low in these patients, so the difference between the intrathoracic pressure and the alveolar pressure is small and the volume calculated with the intrathoracic pressure differs only slightly from the actual TGV.

\section{RESULTS}

TYPE OF FLOW PATTERN During forceful expiration after a full inspiration all subjects had a similar flow pattern. An early peak flow was followed by a rapid decline in flow to a low level. In considering the forced expiratory flow time course, it is convenient to recognize that the early transient peak flow has an ascending limb, a zenith, and a descending limb (Fig. 1). There is then occasionally a rapid fluctuation or flutter as the flow reaches a low level which is sustained, sometimes with a slight rise, until the terminal decline in flow.

FLOW PATTERN AND TGV Ignoring the early peak flow, the maximum expiratory flow volume (MEFV) curve was constructed for each patient by plotting flow against calculated TGV derived from several expirations of varying force. The $\dot{V}$ max obtained at various TGVs during expirations of maximum force were then compared with those of the MEFV curve for each patient. It was found that after the initial peak flow, the $V$ of the forceful expirations usually fitted the MEFV curve ; the rapid drop in flow with the subsequent slow flow rate corresponded to a great reduction 


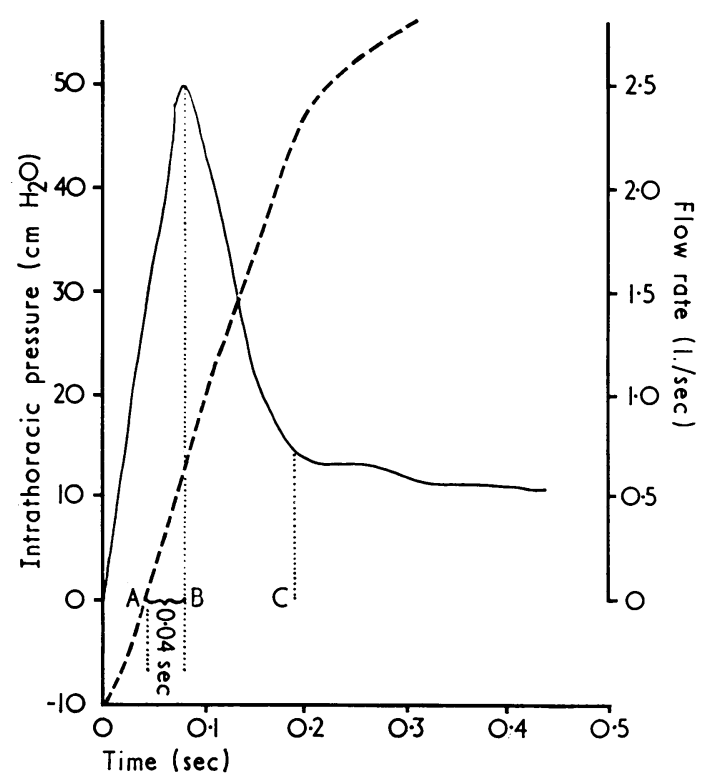

FIG. 1. Flow rate (continuous line) during a forceful expiration shows early peak flow with ascending limb beginning at 0, a zenith reached at $B$, and a descending limb ending at $C$.

The intrathoracic pressure (broken line) passes through atmospheric pressure at $A$. The time interval between $A$ and $B$ was nearly constant and has been termed the zenith flow initiating time interval.

in TGV (Fig. 2). This was due to the high intrathoracic pressure which developed following the peak flow. The slight rise in flow which sometimes occurred during the slow flow phase corresponded to a reduction in the intrathoracic pressure $\left(P_{T}\right)$, allowing some expansion of the TGV even though expiration of air had continued (Fig. 3).

RELATIONSHIP OF TRANSIENT PEAK FLOW TO TGV AND $\mathbf{P}_{\mathrm{T}}$ The peak flow in the early part of expiration did not conform to the pattern observed subsequently. The transient peak was found to 'pop up' through the MEFV curve. The $\dot{V} \max$ exceeded that expected for the corresponding TGV (Fig. 2). Provided sufficient expiratory force was applied suddenly, the zenith flow (ZEF) developed rapidly after expiration of a very small volume of air.

Expiration was found to be initiated at a variable rate and the intrapleural pressure remained subatmospheric for a variable time, particularly during relaxed expirations. Airway compression and flow limitation are unlikely to occur during this phase of expiration. In examin-

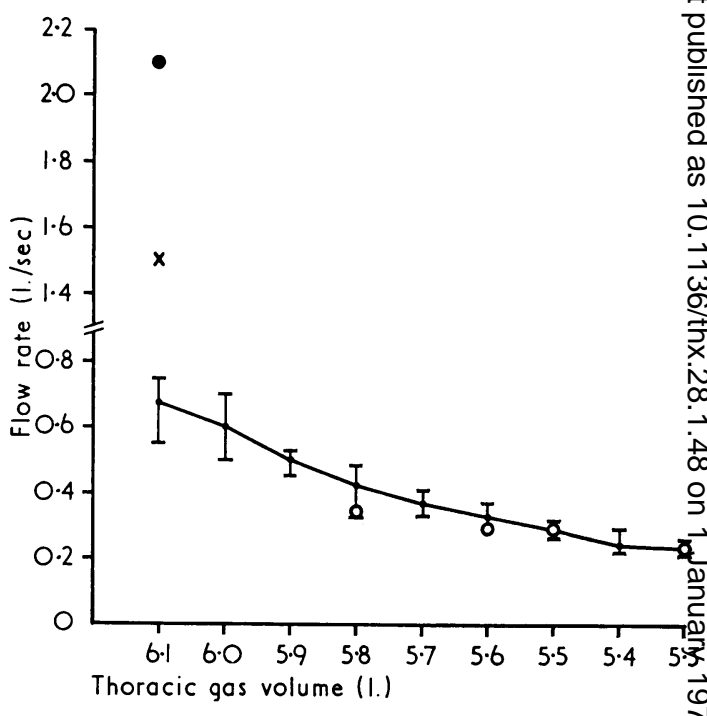

FIG. 2. Maximum expiratory flow volume curve was constructed from the maximum expiratory flows (mean $\$$ three values) plotted against the thoracic gas volume. Th vertical lines represent the range. In constructing the curv? peak flows were ignored. The maximum flows plotted were those observed following the peak flow.

It was found that the maximum flow rates obtaine during expiration of maximum force fitted the $M E F \bar{B}$ curve at various lung volumes, provided the flow rates were those obtained after the peak flow. Flows from a force expiration are shown (0).

At a TGV close to total lung capacity, the peak flo reached a zenith flow (O) which was considerably greated than the corresponding $\dot{\mathrm{V}} \max$ of the MEFV. With expiration of moderate force the zenith flow $(x)$ als exceeded the $\dot{V}$ max of the MEFV curve, but to a lesse degree.

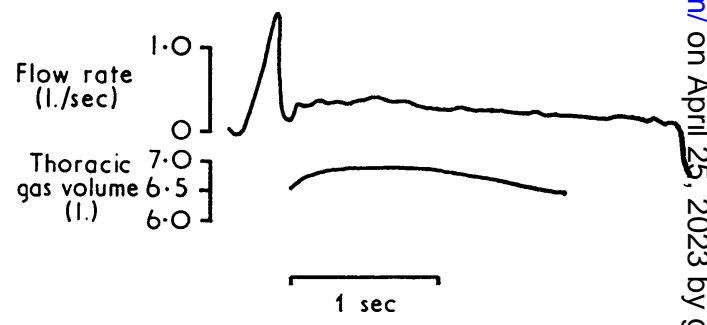

FIG. 3. The flow time course is a tracing during a forct expiration; the corresponding TGV time course w\& constructed from calculated values. After the initial peats flow of a forceful expiration the $T G V$ is considerab $\overline{6}$ reduced due to compression from raised intrathoractic pressure. The TGV then increased due to reduction intrathoracic pressure and the flow also increased; TG $\$$ and flow then remained fairly constant for one secon before gradually reducing. 
ing the time taken for the zenith flow to develop after the airways begin to be compressed, it is relevant to measure the time interval from the start of airway compression, that is when $P_{T}$ is zero, rather than from the initiation of expiration, when $P_{T}$ is subatmospheric. This time interval, zero $\mathbf{P}_{\mathrm{T}}$ to $\mathrm{ZEF}$, was almost invariably between 0.04 and 0.06 second. During this time interval $\dot{V}$ was effort dependent. In Fig. 4, the 'Zenith' $V$ at lung volumes close to TLC have been plotted against the corresponding intrathoracic pressure developed at the time of the zenith flow. It is seen that the zenith flow is related to the intrathoracic pressure and is effort dependent. This relationship held only within the zenith flow initiating time interval of $0.04-0.06$ second. Following this time interval quite large increases of pressure failed to increase the $\vec{V}$ except during the descending limb of the transient peak when flow in forced expiration remained a little above the $V$ max of the MEFV curve.

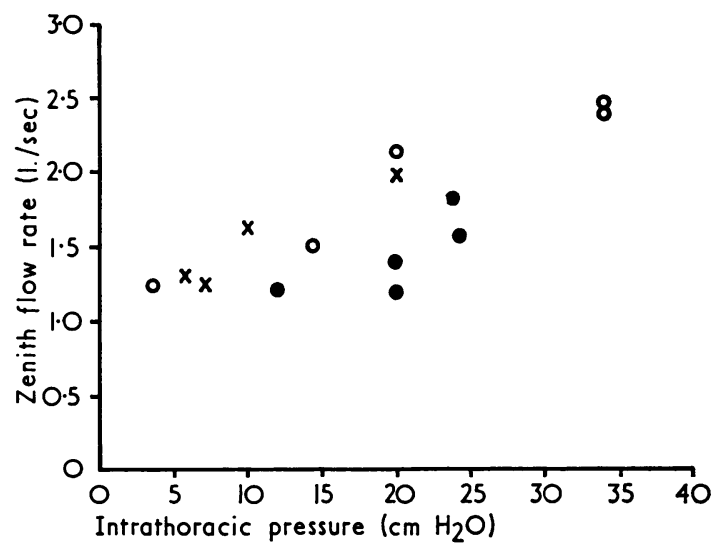

FIG. 4. The zenith flow plotted against the corresponding intrathoracic pressure for three cases. The zenith flow was related to the level of the intrathoracic pressure.

TRANSBRONCHIAL PRESSURE AND PEAK FLOW The intrathoracic pressure is not a reliable indication of the degree of airway compression. This depends upon the transbronchial pressure, that is, the difference between the lateral intraluminal pressure and the intrathoracic pressure. Since the intraluminal pressure has a gradient along the airways, the transbronchial pressure will have a similar gradient and the compressing force will vary along the length of the airways. However, in assessing changes in the compressing force and approximate changes in the degree of compression, it is reasonable to select one site within one bronchus to make comparisons.
For three of the patients intrabronchial pressures within the right lower lobe bronchus were recorded, and from simultaneous recordings of the intrathoracic pressure the transbronchial pressures were calculated during the peak flow. During forceful expirations, the transbronchial pressure increased during a short time interval of approximately 0.2 second after the beginning of expiration. The transbronchial pressure then gradually declined even if the intrathoracic pressure continued to increase. The intrabronchial pressure at this stage increased more rapidly than the intrathoracic pressures, presumably due to increased compression of the larger downstream airways (Fig. 5).

If the peak flow is related to expulsion of air from the conduit airways, it would be anticipated that this would occur only while the compression of the airways is increasing. The right lower lobe transbronchial pressure provides an indication of the compression changes in this and similar sized airways, and with certain limitations in the more peripheral airways. The peak flow (including the ascending and descending limb) corresponded in time to the period in which the transbronchial pressure indicated that the airways were being increasingly compressed (Fig. 5). This is consistent with the hypothesis that air expelled from the compressed conducting airways contributes to the peak flow. However, the zenith flow did not correspond to the transbronchial pressure zenith and it was not related consistently to the rate of change of the transbronchial pressure (Fig. 5). Comparison between a less forceful expiration and a forceful expiration showed that the zenith flow developed with a smaller transbronchial pressure with a less forceful expiration.

PULMONARY RESISTANCE AT ZENITH FLOW The mean of four or five measurements of pulmonary resistance $\left(R_{P}\right)$ at zenith flow has been compared with the mean of four or five measurements of resistance when $\mathbf{P}_{\mathrm{T}}$ was zero (Table II).

T A B L E II

PULMONARY RESISTANCE $\left(\mathrm{cm} \mathrm{H}_{\mathbf{2}} \mathrm{O} / 1 . / \mathrm{sec}\right)$

\begin{tabular}{l|c|c|c|c|c}
\hline & Patient 1 & Patient 2 & Patient 3 & Patient 4 & Mean \\
\hline $\begin{array}{c}\mathrm{P}_{\mathrm{r}}=\text { zero } \\
\text { Zenith flow }\end{array}$ & $\begin{array}{r}4.4 \\
14 \cdot 1\end{array}$ & $\begin{array}{c}6 \cdot 6 \\
11 \cdot 1\end{array}$ & $\begin{array}{c}12 \cdot 5 \\
19 \cdot 8\end{array}$ & $\begin{array}{c}10 \cdot 3 \\
13 \cdot 7\end{array}$ & $\begin{array}{r}8 \cdot 5 \\
14 \cdot 7\end{array}$ \\
\hline Difference & $9 \cdot 7$ & $4 \cdot 5$ & $7 \cdot 3$ & 3.4 & 6.2 \\
\hline
\end{tabular}

$\mathbf{R}_{\mathbf{P}}$ at zenith flow showed a relatively small increase of $6.2 \mathrm{~cm} \mathrm{H}_{2} \mathrm{O} / 1 / \mathrm{sec}$ above the basal $R_{P}$ (when $\mathbf{P}_{\mathbf{T}}=$ zero). As the zenith flow resistance 

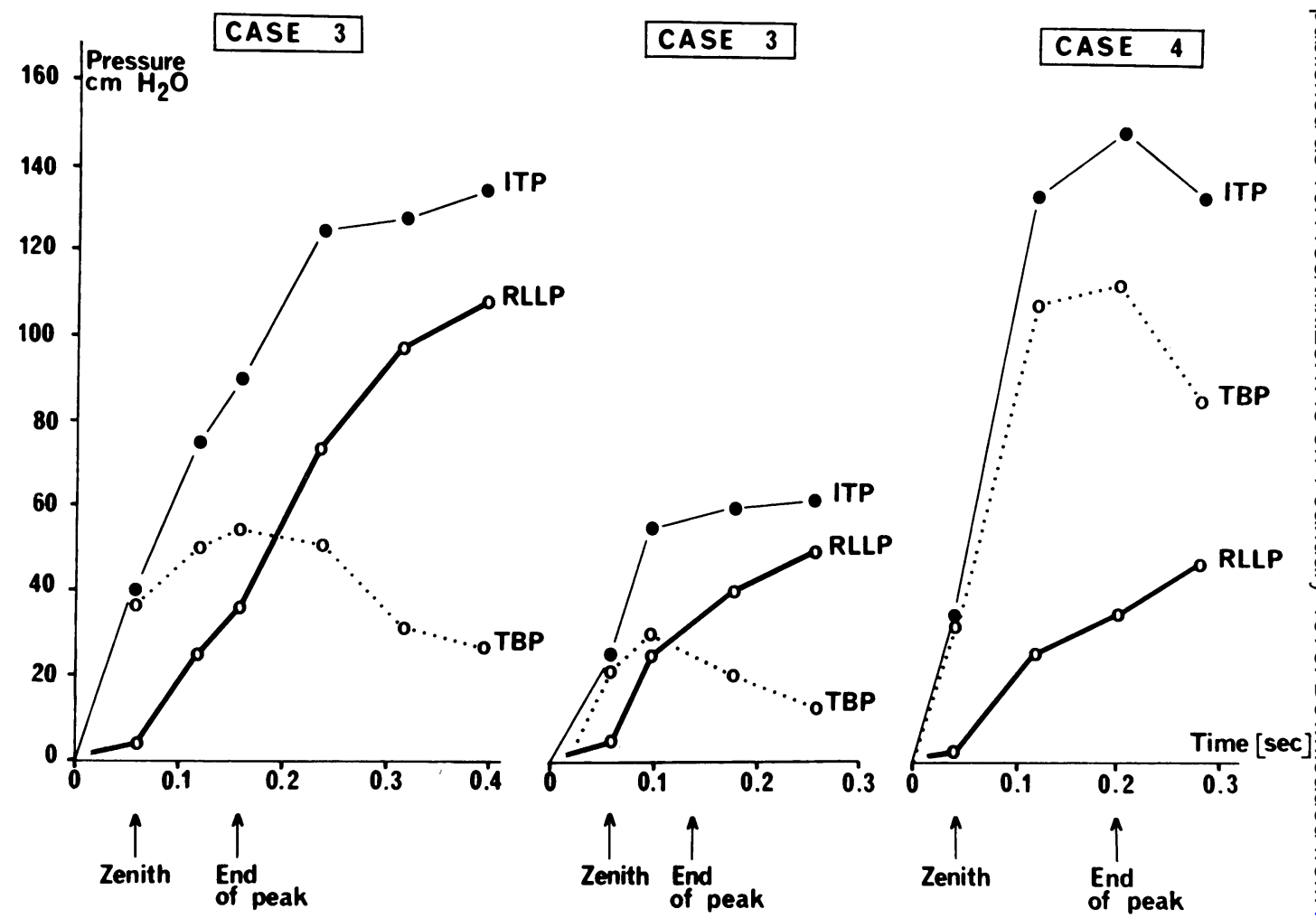

FIG. 5. Intrathoracic pressure (ITP), right lower lobe bronchial pressure (RLLP), and transbronchial pressure (TBPि plotted simultaneously in three separate expirations. The TBP increases early and reaches a maximum before the end o: the peak flow period. Zenith flow does not correspond to maximum TBP and is not consistently related to rate of chang $\overrightarrow{b^{2}}$ of TBP. The RLLP is low in each case at zenith flow.

is measured at a greater flow rate than the basal $R_{P}$, part of the difference in resistance is due to turbulence at the higher flow rate. If it had been possible to measure the two resistances at the same flow rate, the difference between the two would have been less than that found.

INTRATHORACIC PRESSURE ASSOCIATED WITH FLOW LIMITATION As the $\vec{V}$ max ceased to be related to effort immediately following the zenith flow, it appeared that flow limitation developed at this point. This developed at volumes close to TLC. The lowest $P_{T}$ associated with a recognizable

T A B L E II I

LOWEST INTRATHORACIC PRESSURE ASSOCIATED WITH FLOW LIMITATION AT VOLUMES CLOSE TO TLC

\begin{tabular}{c|c}
\hline Patient & Pressure $\left(\mathrm{cm} \mathrm{H}_{2} \mathrm{O}\right)$ \\
\hline 1 & 20 \\
2 & 6 \\
3 & 12 \\
4 & 4 \\
\hline
\end{tabular}

zenith flow was interpreted as being the minimap pressure required to produce flow limitation. This was quite low and could be produced by expiraอ tions of only slight force (Table III).

\section{DISCUSSION}

For the major part of forced expiration the max was found to be related to lung volume. However, this did not apply during the initiab peak flow which considerably exceeded the max of the MEFV curve as constructed.

Tammeling, Sluiter, De Vries, and Berg (1964ф considered that expiratory flow curves could bิ divided into two components. This was achieve of by extrapolating backwards from the flow curve which followed the initial peak. The area (volume? of the peak above the extrapolated line was regare ded as the 'bronchial' component. This was con $\mathbb{8}$ sidered to be superimposed upon the second phase component described as the 'alveolar' componento The 'bronchial' component had a volume of 
about $80 \mathrm{ml}$. It was considered that this represented gas expelled from the bronchial tree by initial tracheobronchial collapse. This simple concept required qualification when it is realized that the second phase flow component from which the extrapolation is made is affected by the reduction of lung volume due to compression by high intrathoracic pressure. The peak flow could exceed the second phase flow because the peak flow is related to a much larger TGV.

In patients with obstructive airway disease the expiratory flow during maximum voluntary ventilation transiently exceeds that of the forced expiratory flow volume curve at the same lung volume (Takishima et al., 1967). The flow transients had a duration of $\mathbf{0 . 2}$ second or less and an estimated $200-300 \mathrm{ml}$ was displaced. It was estimated that there was a small region with a short time constant and a larger region with a much longer time constant. The anatomical basis for these observations was uncertain. The small rapid region was too large to be accounted for entirely by displacement from dynamically compressed airways. However, Knudson, Mead, and Sherry (1970) reported that the volume displacement was less, about $150 \mathrm{ml}$. They considered it was possible that displacement from the conducting airways could account for the short time constant.

In the cases examined in the present investigation, the compressing force increased during a time interval of approximately 0.2 second ; during this time the peak flow exceeded the $\dot{V}$ max of the MEFV curve, supporting the possibility that the transient flow volume is derived from compression of the conduit airways. However, the zenith flow was not consistently related to the rate of change or the maximum level of the compressing force.

This lack of correspondence between the zenith flow and the compressing force might reflect inaccuracies due to the measurements of the bronchial compressing force at only one site. Alternatively, the degree of compression of the airways is not always proportional to the com. pressing force. Although these factors cannot be dismissed entirely, they are unlikely to have caused discrepancies of sufficient degree to account for the lack of correlation between the zenith flow and the transbronchial pressure recordings. Consequently, it is advisable to consider whether another factor might influence the zenith flow, if not the peak as a whole.

It is possible for compression of the airways to lag behind the compressing force. The zenith flow during a forced expiration appeared to mark the beginning of flow limitation. This point was reached in a short and relatively constant time interval. Within this interval, flow was effort dependent. This is consistent with there being a time lag before flow limitation developed. This time lag would include the brief time taken for the intrathoracic pressure to exceed the intrabronchial pressures and, secondly, the time taken for the airways to narrow when subjected to the compressing force. That a finite time is required for the airways to narrow and produce flow limitation receives support from the observation that at the zenith flow, i.e., the point of development of flow limitation, pulmonary resistance had increased only a little above basal levels. This would be consistent with only slight airway compression to this point, despite a rapidly increasing compressing force. The bronchial pressure recording at the beginning of flow limitation was low, which is also consistent with little compression of the larger airways at this stage.

A lag in the development of flow limitation would permit the flow rate transiently to exceed the $\dot{V} \max$ of the MEFV curve, which is the maximum flow achieved after flow limitation has been established.

Once flow limitation has begun, the intrathoracic pressure increases considerably and bronchial pressure readings indicate that the larger airways then become compressed. The degree probably depends upon increased compliance of some of the larger airway walls, as reported previously (Campbell and Faulks, 1969). The effect of the compression of the larger airways on flow limitation depends upon its influence on the position of the equal pressure points.

Points where the pressure at the inner wall of the airway are equal to the $P_{T}$ are called equal pressure points (EPP). Upstream to the EPP the intraluminal pressure will exceed the $P_{T}$ and airway compression will not occur. Downstream to the EPP, the $P_{T}$ will exceed the intraluminal pressure and airway compression can occur.

It is realized that the force outside the airways may not equal $P_{T}$ (Pratt, 1968). If so, the EPP will be in a slightly different position from that measured. However, this difference is unlikely to be sufficiently large to alter the general principles.

There are two main theories concerning the mechanics of flow limitation. Pride, Permutt, Riley, and Bromberger-Barnea (1967) held that just downstream from the EPP critical narrowing occurs in the form of a 'resistor', regulating the maximum flow. Mead, Turner, Macklem, and Little (1967) believed that all airways downstream 
to the EPP, not just those close to the EPP, may contribute to flow resistance. It is argued by both groups that the position of the EPP at any lung volume is of primary importance in determining $\dot{V} \max$ at that lung volume. For example, according to Mead et al. (1967), the driving pressure for the airways upstream of EPP will be alveolar pressure minus intrathoracic pressure, which equals the static recoil pressure at that lung volume. The $\dot{V}$ max will then depend upon the recoil pressure and the resistance (frictional and accelerative) of the upstream segment. As the flow is in series, the flow through the downstream segment will be fixed by that of the upstream segment. The downstream segment can, however, affect $\dot{V} \max$ by influencing the position of the EPP. Increased compression of the larger airways, by increasing flow resistance, increases the pressure in the upstream bronchi. This will move the position of EPP downstream. The length of the upstream segment is increased and hence the flow resistance through the segment upstream to the EPP will be increased in this manner. The downstream airways could also alter the position of the 'resistor' of Pride et al. (1967) in a similar manner and reduce $\dot{V}$ max also. The position of the EPP was not determined exactly in the investigated patients, but it was found to move from the mouth to become more peripheral than the lobar bronchi at the zenith of the transient peak early in expiration.

Owing to its peripheral position, changes in the site of the EPP could not be recorded, but the increased pressure in the lobar bronchi, which occurred following peak flow, would be expected to move the EPP downstream, particularly in case 3 . The isovolume $\dot{V} \max$ would then be reduced as the intrathoracic pressure increased and the larger airways became compressed. However, the reduction in maximal flow due to a rather small change in the position of EPP is likely to be small. It would appear that the tracheobronchial collapse observed bronchoscopically in these patients exerted only slight or no effect on maximum flow.

Patients with tracheobronchial collapse are often found to have a larger expiratory volume in one second when the expiratory effort is relaxed $\left(\mathrm{REV}_{1}\right)$ rather than forced $\left(\mathrm{FEV}_{1}\right)$.

It has been suggested that forceful expiration produces tracheobronchial collapse, thereby reducing the flow rate to a greater degree than when tracheobronchial collapse is avoided during a relaxed expiration. However, tracheobronchial collapse appeared to have only a slight effect on maximum flow. Flow limitation developed after the application of low intrathoracic pressures in the patients investigated and usually developed with relaxed expirations of only moderate force.

An important reason for the $\mathrm{FEV}_{1}$ being less क than the $\mathrm{REV}_{1}$ was that forceful expirations con- $\overrightarrow{0}$ siderably increased the intrathoracic pressure and the TGV was reduced by compression. Most of $\vec{\omega}$ the forced expiratory flow occurred at a lower TGV than during a relaxed expiration. Because $\vec{x}$ of the relationship between the TGV and maxi- i mum expiratory flow, the flow obtained during the $\mathrm{FEV}_{1}$ was less than during the $\mathrm{REV}_{1}$.

\section{REFERENCES}

Campbell, A. H., and Faulks, L. W. (1969). Bronchial pressure measurements in patients with tracheobronchial $\underset{\omega}{\omega}$
collapse. Respiration, 26, 63.

Hyatt, R. E., Schilder, D. P., and Fry, D. L. (1958). Relationship between maximum expiratory flow and degree of lung inflation. J. appl. Physiol., 13, 331.

Ingram, R. H., and Schilder, D. P. (1966). Effect of thoracic gas compression on the flow-volume curve of the forced $\frac{0}{8}$ vital capacity. Amer. Rev. resp. Dis., 94, 56.

Jordanoglou, J., and Pride, N. B. (1968). A comparison of $\overrightarrow{\vec{O}}$ maximum inspiratory and expiratory flow in health and 3 in lung disease. Thorax, 23, 38.

Knudson, R. J., Mead, J., and Sherry, D. E. (1970). Dynamic behavior of conducting airways in chronic obstructive lung disease. Abstract. Amer. Rev. resp. Dis., 101, 453.

Mead, J., Turner, J. M., Macklem, P. T., and Little, J. B. 음 (1967). Significance of the relationship between lung $x$ recoil and maximum expiratory flow. J. appl. Physiol., 22, 95 .

Milic-Emili, J., Mead, J., Turner, J. M., and Glauser, E. M.ळ̊ (1964). Improved technique for estimating pleural pressure from esophageal balloons. J. appl. Physiol., 응 19, 207.

Pratt, P. C. (1968). Intrapulmonary radial traction: measure $=\frac{D}{2}$ ment, magnitude and mechanics. In Current Research in Chronic Respiratory Disease: Proceedings Eleventh Aspen Emphysema Conference, Aspen, Colorado, 1968, p. 159. U.S. Department of Health, Education and N Welfare, Arlington, Virginia.

Pride, N. B., Permutt, S., Riley, R. L., and Bromberger $\frac{\omega}{\sigma}$ Barnea, B. (1967). Determinants of maximal expiratory flow from the lungs. J. appl. Physiol., 23, 646.

Takishima, T., Grimby, G., Graham, W., Knudson, R. Macklem, P. T., and Mead, J. (1967). Flow-volume curves during quiet breathing, maximum voluntaryo ventilation and forced vital capacities in patients witho obstructive lung disease. Scand. J. resp. Dis., 48, 384.

Tammeling, G. L., Sluiter, H. J., De Vries, K., and Berg吕 W. C. (1964). Evaluation of bronchoconstriction and bronchodilation from a forced expiration. In Bronchitis Second International Symposium, Groningen, The Netherlands. 